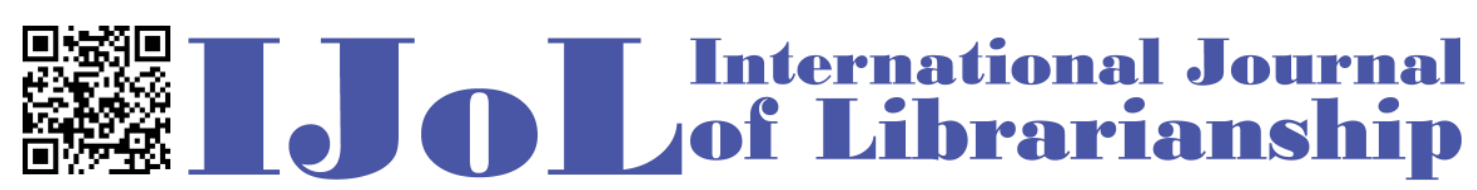

ISSN: 2474-3542 Journal homepage: http://journal.calaijol.org

\title{
Adapting to a Dynamic Higher Education Environment - How the University of Glasgow Library Is Taking Up the Challenge
}

Susan Ashworth

\begin{abstract}
:
The University of Glasgow Library is continuously developing space and services to meet the need of students and researchers in an evolving higher education landscape. We are an evidence-based organisation and have used tools such as ethnography, surveys and focus groups to understand how users interact with the physical and virtual library. We have also introduced new roles and created new partnerships across the University, particularly in the context of the United Kingdom Government's policy on open access and funder requirements for the management of research data.

This paper will focus on how the University of Glasgow Library is adapting to both the dynamic scholarly communications environment and the demands of our national research exercise and evidence from users and changing student needs.

Every six years in the UK, there is a national research assessment exercise called the Research Excellence Framework (REF) and measurement of the performance of research outputs is a key part of that exercise. From 1st April 2016, in order to be eligible for the next REF, the accepted final version of journal articles and conference proceedings must have been deposited into an institutional repository within three months of the date of acceptance and made open access. Many research funders, such as the Wellcome Trust, also have policies on open access. The Library, in close partnership with the University's Research Office, has taken the lead in publicising these policies to ensure that researchers are aware of their responsibilities. It has also developed new functionality in Enlighten, our institutional repository service to support compliance.
\end{abstract}

In 2015, the Library commissioned an in-depth ethnographic study to help us more readily understand the changing needs of students and how they use library space. An overview of the results of this work and our next steps will demonstrate how we are "enabling progress".

To cite this article:

Ashworth. (2016). Adapting to a dynamic higher education environment - how the University of Glasgow Library is taking up the challenge. International Journal of Librarianship, 1(1), 55-65. https://doi.org/10.23974/ijol.2016.vol1.1.15

To submit your article to this journal:

Go to http://ojs.calaijol.org/index.php/ijol/about/submissions 


\title{
Adapting to a Dynamic Higher Education Environment - How the University of Glasgow Library Is Taking Up the Challenge
}

\author{
Susan Ashworth \\ University of Glasgow Library, Glasgow, Scotland, UK
}

\begin{abstract}
The University of Glasgow Library is continuously developing space and services to meet the need of students and researchers in an evolving higher education landscape. We are an evidence-based organisation and have used tools such as ethnography, surveys and focus groups to understand how users interact with the physical and virtual library. We have also introduced new roles and created new partnerships across the University, particularly in the context of the United Kingdom Government's policy on open access and funder requirements for the management of research data.

This paper will focus on how the University of Glasgow Library is adapting to both the dynamic scholarly communications environment and the demands of our national research exercise and evidence from users and changing student needs.

Every six years in the UK, there is a national research assessment exercise called the Research Excellence Framework (REF) and measurement of the performance of research outputs is a key part of that exercise. From 1st April 2016, in order to be eligible for the next REF, the accepted final version of journal articles and conference proceedings must have been deposited into an institutional repository within three months of the date of acceptance and made open access. Many research funders, such as the Wellcome Trust, also have policies on open access. The Library, in close partnership with the University's Research Office, has taken the lead in publicising these policies to ensure that researchers are aware of their responsibilities. It has also developed new functionality in Enlighten, our institutional repository service to support compliance.

In 2015, the Library commissioned an in-depth ethnographic study to help us more readily understand the changing needs of students and how they use library space. An overview of the results of this work and our next steps will demonstrate how we are "enabling progress".
\end{abstract}

Keywords: Open Access, Research Excellence Framework, United Kingdom, Research Data Management, Ethnography, Students, Library Space

\section{INTRODUCTION}

This paper examines two ways in which changes in the higher education environment in the United Kingdom are impacting on libraries. The strong move towards open access that was introduced by the UK Government in 2012 is influencing the requirements research funders place on universities and individual researchers. They, in turn, are looking to libraries to advise and guide them through 
complex open access policies, publisher copyright and licensing agreement and payment of article processing charges. There have also been significant changes in the funding environment for students in parts of the UK, with the cap for fees raised to $£ 9 \mathrm{k}$ per annum for undergraduate degree programmes in 2010. Many research-intensive universities have also significantly raised their targets for recruitment of international students. Arguably, this has raised expectations amongst students attending UK universities and their expectations of university libraries, from study spaces to virtual services and content (Showers, 2013). Libraries are looking at ways to understand better student expectations and behaviours in order to ensure space and services are optimally matched to need.

\section{OPEN ACCESS TO RESEARCH OUTPUT IN THE UK}

In 2012, the United Kingdom Government created a working group to investigate the best way of expanding access to published research findings, in particular seeking to ensure that the funders of research (in this case the UK taxpayer) were freely able to access the outputs of that research, most of which currently sits behind a subscription paywall. This independent working group, chaired by Dame Janet Finch, had members from the research community, research funders, publishers and higher education libraries. The group published its report in June 2012 (Finch, 2012). The report made several observations about the current scholarly communications system, in particular that the Working Group believed that this system is in transition towards open access. The transition that the Working Group predicted was a flip from the subscription based model under which most publishers sell journals, to an author pays model whereby individual authors pay an article processing charge in order to publish their work which is then open access at the point of publication. This effectively led the Finch Working Group to recommend the Gold model of open access.

The United Kingdom Government endorsed the Finch Report. It is now Government Policy and has been adopted by research funders such as the Research Councils UK (RCUK). RCUK published their policy on open access in May 2013 (RCUK, 2013) and at the same time introduced a new funding mechanism to support this policy in the form of a block grant to eligible institutions to cover the costs of article processing charges (APCs). In 2015/16 the University of Glasgow received $£ 547,403$ to cover the costs of APCs for papers which acknowledge a RCUK grant.

In the UK, around once every six years, there is a national research assessment exercise, the Research Excellence Framework (REF). Researchers in UK universities are asked to select their top four publications for submission to this exercise. The assessment of outputs counted for $60 \%$ of the overall score in the 2014 Research Assessment Framework. The REF also assesses the research environment and the impact of research. The results then determine how much research funding institutions are granted.

The Higher Education Funding Councils for the United Kingdom carried out a consultation on whether open access should be a key requirement for future REF exercises and on the $1^{\text {st }}$ April 2015, the new REF open access policy came into effect (Higher Education Funding Council for England, 2015).This policy applies only to journal articles and conference proceedings with an ISSN at the moment, however it should be noted that over $80 \%$ of the University of Glasgow's submission to REF 2014 was journal articles. Therefore, ensuring that our researchers understand and comply with this policy is incredibly important.

The main open access eligibility requirement of the REF is that the accepted final version of the journal article or conference proceeding must have been deposited into an institutional or subject repository within three months of the date of acceptance of the paper (this requirement has been relaxed during the first year of the policy so that deposits can take place at any point during the 
publication cycle up until three months after the date of publication). Once deposited, journal embargo policies can be applied before the paper is made freely available as long as they do not exceed 12 months for STEM subjects or 24 months for Humanities and Social Science subjects. The REF open access policy has three main requirements:

- Deposit - the paper must have been deposited into an institutional or subject repository within three months of the date of acceptance,

- Discovery - the paper must have a metadata record that allows it to be discovered by search engines,

- Access - the paper should be freely available for anyone to search within the text, read and download after any acceptable embargo period has lapsed.

The REF open access policy depends on researchers acting at the point of acceptance. Many institutions collect information about the publications made by their staff and they do this in a number of ways, including using APIs to bring in data from indexing and abstracting services such as Web of Science and Scopus. Of course, this data is being collected after the publication of the paper and the requirement to know about publications at the point of acceptance poses some challenges. There are no abstracting databases which index publications at the acceptance stage and therefore institutions have to rely on authors supplying this data themselves. That said, the author is far more likely to have the accepted version of the paper to hand at the acceptance stage than when the paper is finally published (in some subjects this can be years after the acceptance date).

Other research funders also have open access requirements and a group of biomedical charities in the UK have formed the Charity Open Access Fund (COAF), led by the Wellcome Trust (Wellcome, n.d.). COAF also makes a block grant to eligible universities to cover the costs of article processing charges for papers which acknowledge their grants and the University of Glasgow received $£ 160,000$ in 2015/16. The Wellcome Trust has been a strong supporter of open access for many years and sees it as a fundamental part of its charitable mission to ensure the widest possible audience for the work that it funds. The Wellcome Trust is unusual in extending their open access policy to cover scholarly monographs and book chapters, and the Trust also has potential sanctions for researchers who do not comply with their policy, which might include withholding grant funding and discounting non-compliant papers from new grant applications.

Some funders in the United Kingdom have also introduced policies on the management and retention of the research data created from research projects which they have funded. These policies support free access to and re-use of these datasets and many institutions are setting up support for research data management, both in the form of infrastructure and staffing.

The open access policies of government and funders in the UK have an underlying aim to create change in the way that scholarly communications are conducted, in particular to move publishers from subscription based models to gold open access models and to create a market amongst journals which will drive down costs. Funders in the UK are currently satisfied when their funds are used to pay for open access in hybrid open access journals (subscription journals where some of the articles are open access) as well as pure open access journals. In practice, this means that the scholarly communications model is not being particularly disrupted. However, there are problems associated with hybrid open access, for example that APCs are often more expensive than for pure open access journals. The Wellcome Trust has recently published a blog post which analyses spend from the COAF open access budget in 2014-15 (Kiley \& Marden, 2016). This blog looks at services publishers are providing to support open access and concludes that non-compliance with their open access policy is far more prevalent in hybrid journals. One way in which funders are addressing 
these issues in other countries (for example the EU FP7 Open Access Pilot) is not to allow their open access funds to be used for hybrid journals.

Open access to publications and to research data, in the United Kingdom, is a significant requirement of researchers working in publicly funded higher education institutions. Noncompliance with these policies may affect the future of an individual researcher - their ability to obtain grant funding or their potential submission to the Research Excellence Framework. Furthermore, it may affect the institution - particularly if significant numbers of papers have to be discounted from future submissions to the REF. The open access policies of these research funders all differ in their detail and requirements, publishers' policies on open access are all different, embargo periods vary from journal to journal, mechanisms for the payment of article processing charges vary from publisher to publisher. The open access landscape in the UK is difficult for researchers to navigate and Libraries have been considering how they can best support their researchers in this new open access environment.

\section{SUPPORTING RESEARCHERS WITH OPEN ACCESS AND RESEARCH DATA MANAGEMENT}

At the University of Glasgow Library, we decided in early 2013 that our open access service should be focussed on taking the strain away from researchers. We have a very simple message for our academics - as soon as you have a paper accepted for publication email the Library and we'll do the rest.

We discuss this as two sets of responsibilities: the first responsibility sits with the researcher - to let the Library know as soon as they have a paper accepted; the second set of responsibilities sits with the Library - once notified of an accepted paper the Library will advise on the appropriate open access pathway for that paper. This includes checking whether there is a funder requirement for open access; checking the publisher's open access and copyright policies; paying an article processing charge, if appropriate; depositing the manuscript and releasing after any embargo period; reporting within the University and to research funders on compliance with open access policies; and lastly, ensuring that any underlying dataset is acknowledged in the paper, recorded in the University's data registry, stored and curated appropriately.

The Library has been delivering this service for three years and we have come across many challenges, not least because the Library is stepping into the middle of the publisher-author relationship and publisher systems were not set up to enable this intermediate role (Ashworth, Mccutcheon, \& Roy, 2014). Systems and workflows are improving, both within institutions and with publishers, however support for open access is staff intensive and is creating significant new areas of work for University Libraries in the UK. At the University of Glasgow, we are considering how to scale up our service to meet the significantly growing demand. An indication of this demand is the huge increase in open access content in our institutional repository which, in some subject areas, sits at $80 \%$ or more.

Open access is also enabling the Library to create new relationships with our researchers, who see us as a critical partner in their scholarly communications workflow. Researchers at the University of Glasgow have a very high regard for the Library's open access and research data management services as they remove a significant part of the administrative burden of open access compliance.

Open access and research data management services are also attracting new kinds of staff to work in libraries. At Glasgow, staff with research and research administration backgrounds are bringing new perspectives and ideas into the Library environment. 


\section{DEVELOPING OUR INSTITUTIONAL REPOSITORY SERVICE (Enlighten)}

The University of Glasgow has a mature institutional repository service which we have branded Enlighten. The Enlighten brand covers a set of repositories. We currently have three repositories: Enlighten Publications, Enlighten Theses and Enlighten Research Data which are all crosssearchable and are interlinked. (See Figure 1). There are teams which support these repositories and the brand is recognised across the University.

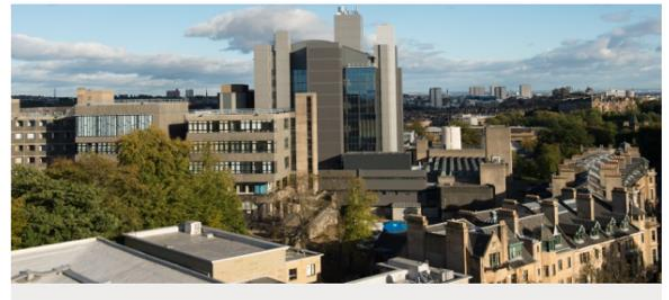

Enlighten: Search
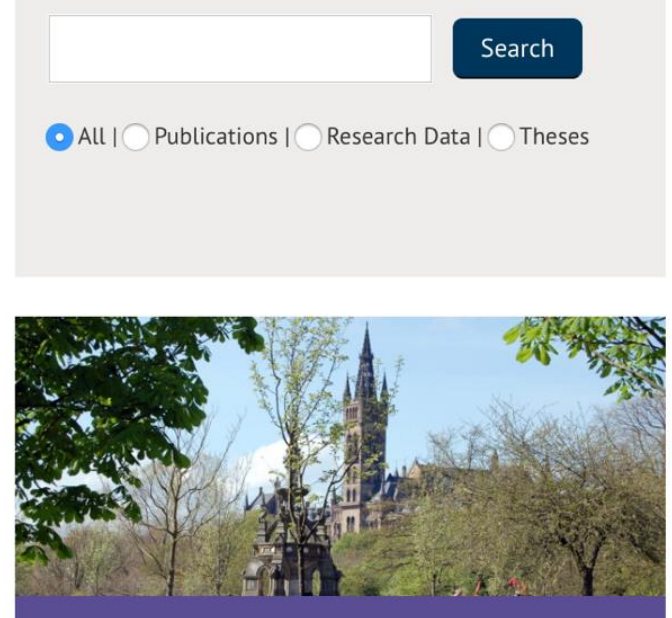

Enlighten: Theses

$\mathrm{PhD}$ and other research degree theses
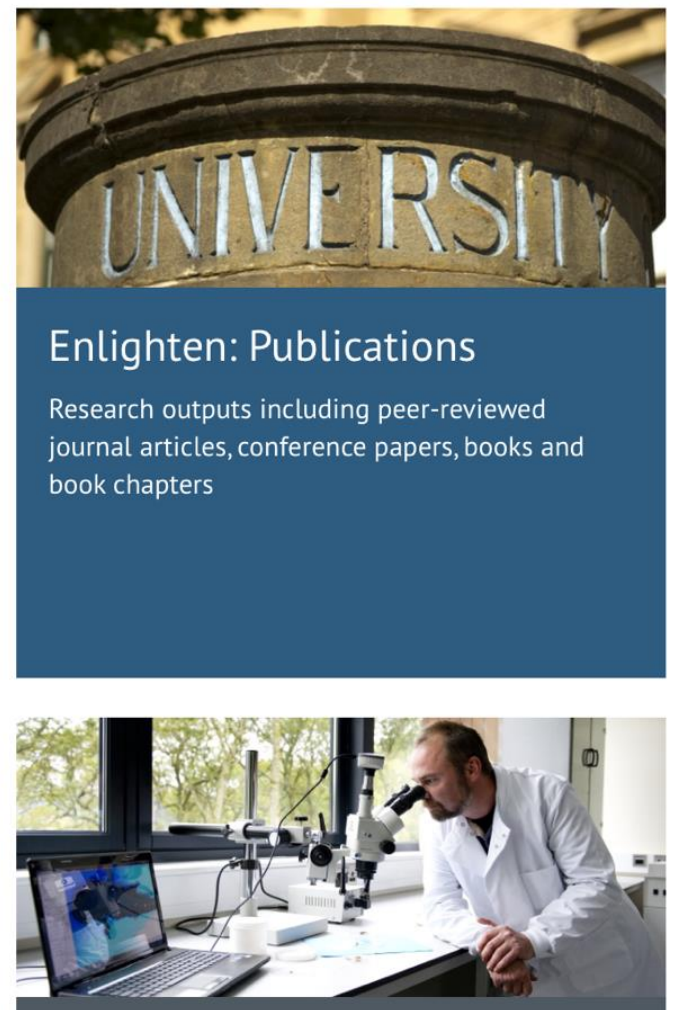

\section{Enlighten: Research Data}

Research data produced at the University of Glasgow including datasets from a variety of disciplines many of which are associated with research publications

Figure 1. Enlighten

The repositories are also linked to other systems in the University including the Human Resources system, the Research System and the Content Management System. This enables the two-way flow of data so that data from these systems can populate Enlighten and data from Enlighten is re-used for University purposes. This has allowed the disambiguation of author names in the repository as the University's unique identifier (GUID) is used to identify each staff member in the repository and, where relevant, details of research projects are pulled into Enlighten from the Research System. An example of the flow of data from Enlighten is the University staff pages which include 
lists of publications and research datasets dynamically pulled from Enlighten (University of Glasgow, n.d.). See Figure 2.

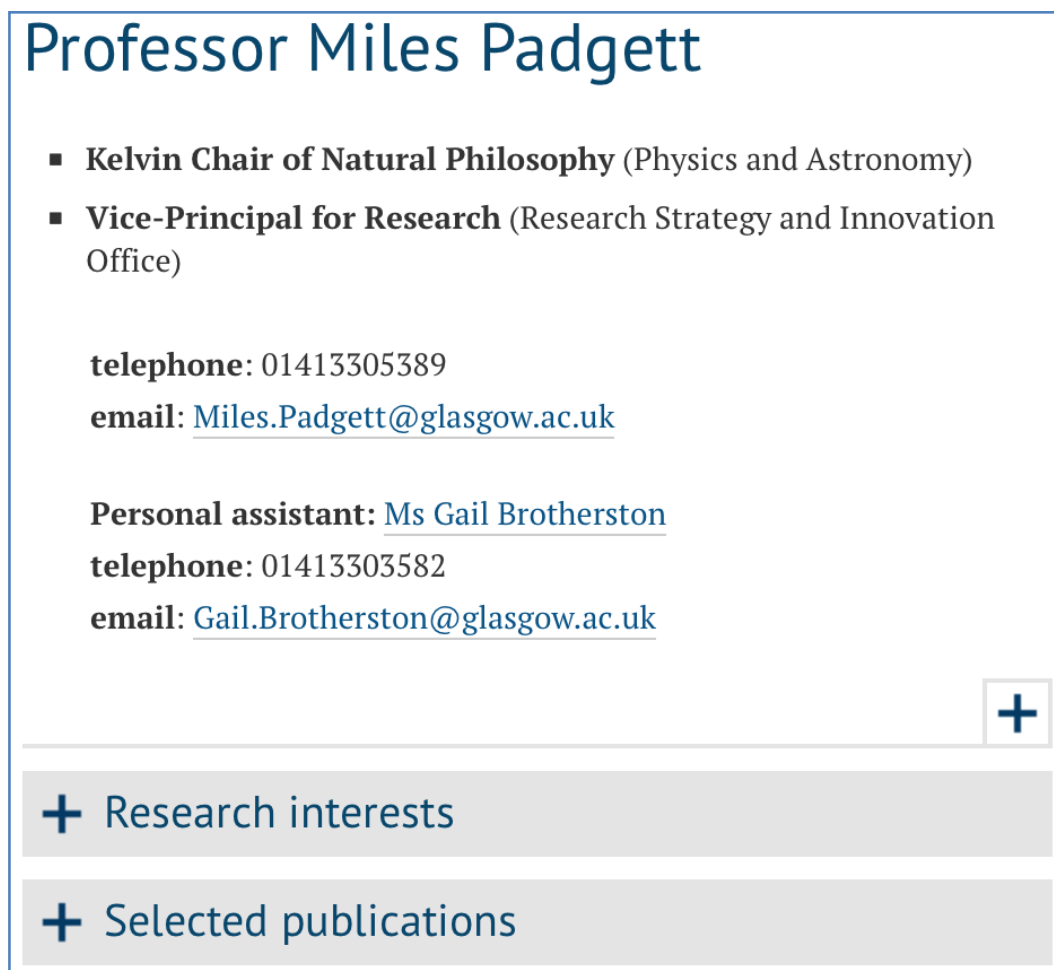

\section{Research data}

Number of items: 2 .

$-2015$

Giovannini, D. and Romero, J. and Potoček, V. and Ferenczi, G. and Speirits, F. and Barnett, S. M. and Faccio, D. and Padgett, M. J. (2015) Spatially structured photons that travel in free space slower than the speed of light. [Data Collection]

Figure 2. Staff profile page

The developing open access environment in the UK is also driving changes to our repositories. We now have to ensure that the acceptance date of publications is recorded against each journal article or conference proceeding, and we have developed fields to record details about the open access status of papers in our repository (McCutcheon \& Eadie, 2016). Figure 3 shows the Enlighten Open Access fields. These include whether the paper is open access via a green or gold route; the costs of any APC paid and/or whether research datasets are acknowledged in the paper. 


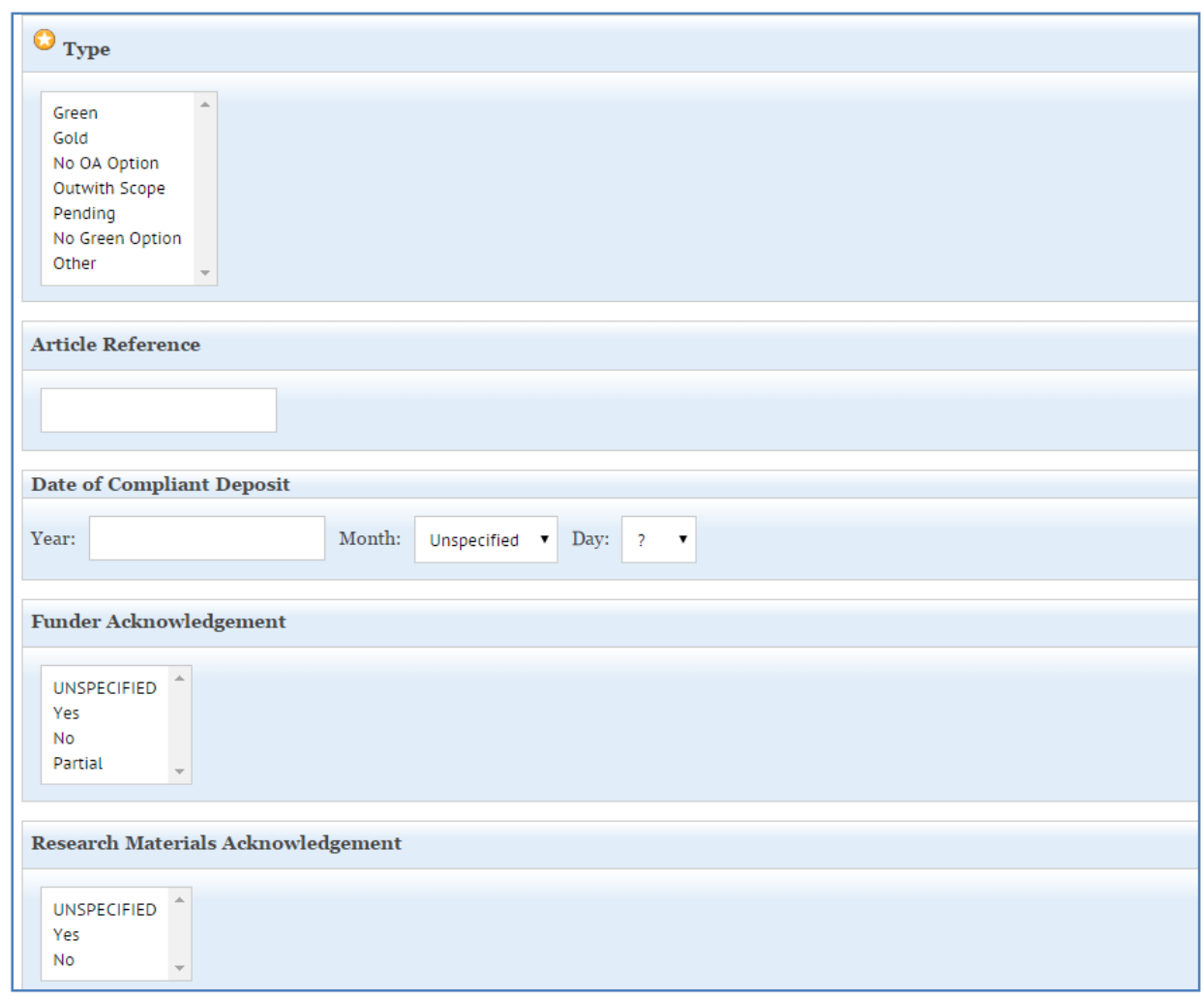

Figure 3. Enlighten Open Access fields

We can also export reports directly from Enlighten which we use to discuss progress towards open access with our Colleges and Schools, and which we can provide to research funders who want to know how well our researchers are complying with their open access policies. See Figure 4.

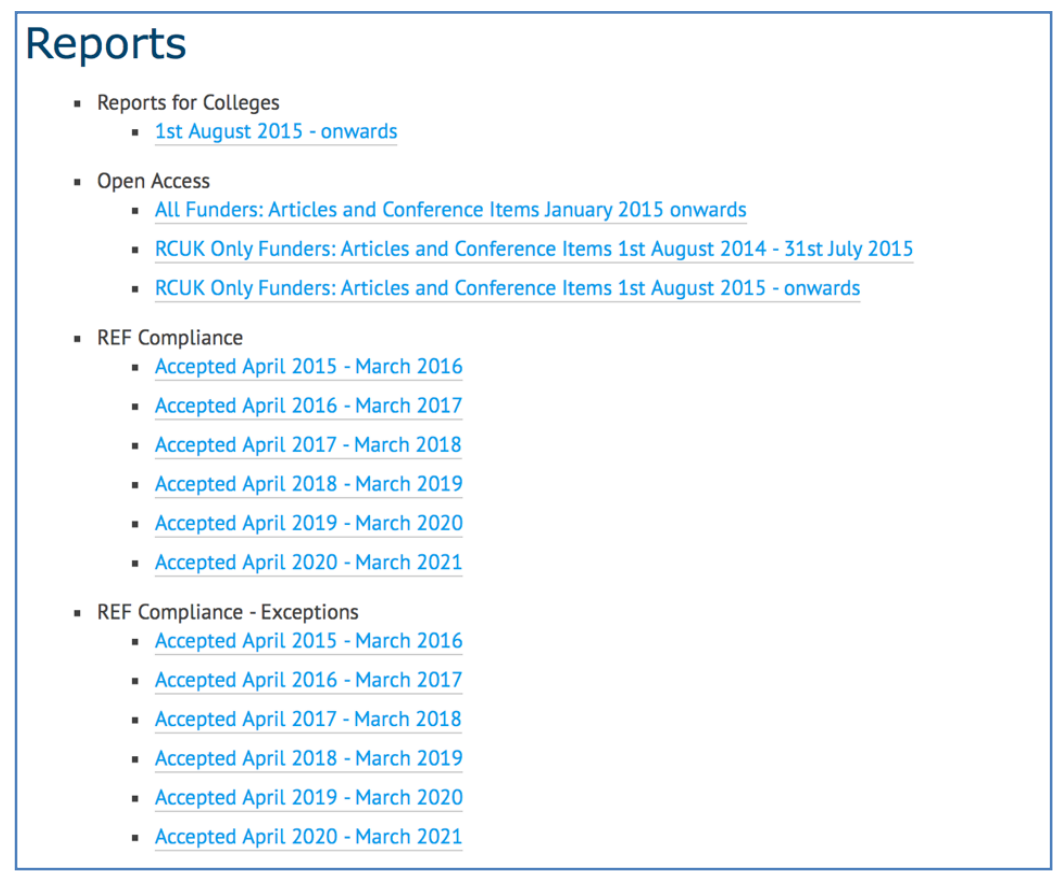

Figure 4. Enlighten Reports 
Academic libraries are continuously evolving and developing to ensure they provide services and support which are relevant to their users. The new services we are developing to support open access and research data management are one example of how academic libraries are stepping up and into new areas of activity. Another example is how libraries are seeking to understand their users better and using that data to inform the development of services which are more customerfocussed. This takes the Library beyond its own perceptions of customer-service and challenges these perceptions.

\section{EVIDENCE-BASED APPROACH AND ETHNOGRAPHY}

At the University of Glasgow Library, we are regularly engaged with our users. As such, we take an evidence-based approach to service development and we have created an Evidence-Base Group to establish an appropriate framework that can be used to make informed decisions that lead to resources and services that are successful for the Library and our user community. The adoption of an evidence-based strategic approach with clear aims and objectives provides a framework within which all service decision-making and evaluation, regardless of scale or cost, is undertaken.

The Library collects evidence from many different sources, including user surveys, which give us a rich picture of the customer experience. We collaborated with Innovative Library Management Systems, Sero Consulting and six other UK academic institutions in 2015 on a major survey of the Online Library to which Glasgow had over 2000 responses including many free text comments (Carter, 2015). We have also received feedback from surveys such as the National Student Survey and the International Student Barometer conducted in the UK and we have used the LibQual survey tool (Association of Research Libraries, n.d.). We collect usage data for our content as well as data from University systems such as the Library's controlled entry system. However, we wanted to have an even deeper understanding of the user experience. To this end, we worked with a company in late 2015, Alterline (http://alterline.co.uk/), who carried out in-depth customer experience analysis using tools such as ethnography and observation.

Ethnographic approaches rely less on what users tell you about their experience and instead use observation techniques, including videoing user journeys, to understand the actual user experience. Taking this into consideration, we are currently redeveloping space in the Main Library, and the University of Glasgow is building a new Learning and Teaching Hub so the timing of this user experience work was ideal for informing both of these projects.

Alterline used a mix of approaches to understand the user experience. These included ethnographic observation which took place in the Library on three separate occasions, including later at night during the latter part of 2015 (the Library is open between 7am and 2am, 361 days a year). Alterline also conducted semi-structured interviews with a number of students to find out their reason for being in the Library that day and their experiences of the Library generally. We found that students were very responsive to this approach and very willing to allow themselves to be videoed and to provide constructive feedback about the Library. This may have been helped by the youthful Alterline staff so that participation felt more like peer to peer discussion.

The ethnographic work was designed to capture touchpoints on the user journey, and particularly pinch-points which may hinder or prevent users from reaching their goal. The company produced videos which clearly demonstrate where user journeys break down and which will help us to identify areas for improvement.

The work carried out in the Main Library focussed on students and their use of the Library. We also asked Alterline to work with researchers so that we could have a better understanding of how 
researchers use Library buildings, content and services. This work was done largely through focus groups and structured interviews.

\section{Key messages from our users}

- Students want different kinds of study space depending on personal preference and the type of work they are doing.

- Group study is a critical activity.

- Students do not find navigation of the building, cataloguing system, technology (such as self-issue, printing) problematic.

- Students might be based in the Library all day and they want to be able to meet up with their friends, socialise, get food, and leave their belongings.

- The Library environment facilitates studying, students are comfortable in the Library and they treat the Library like home.

- Students prefer a modern environment and avoid some of the older spaces.

- The University of Glasgow Library is a twelve storey building with services concentrated on the entrance level to the building - students want more help where they are located.

- Researchers do not use the physical library (perceiving it to be for undergraduate students).

- Researchers do not always find the Library's discovery tools effective and often resort to using external search engines.

- Researchers are increasingly using social media to stay up-to-date.

Figure 5 is a photograph of students socialising in the Library.

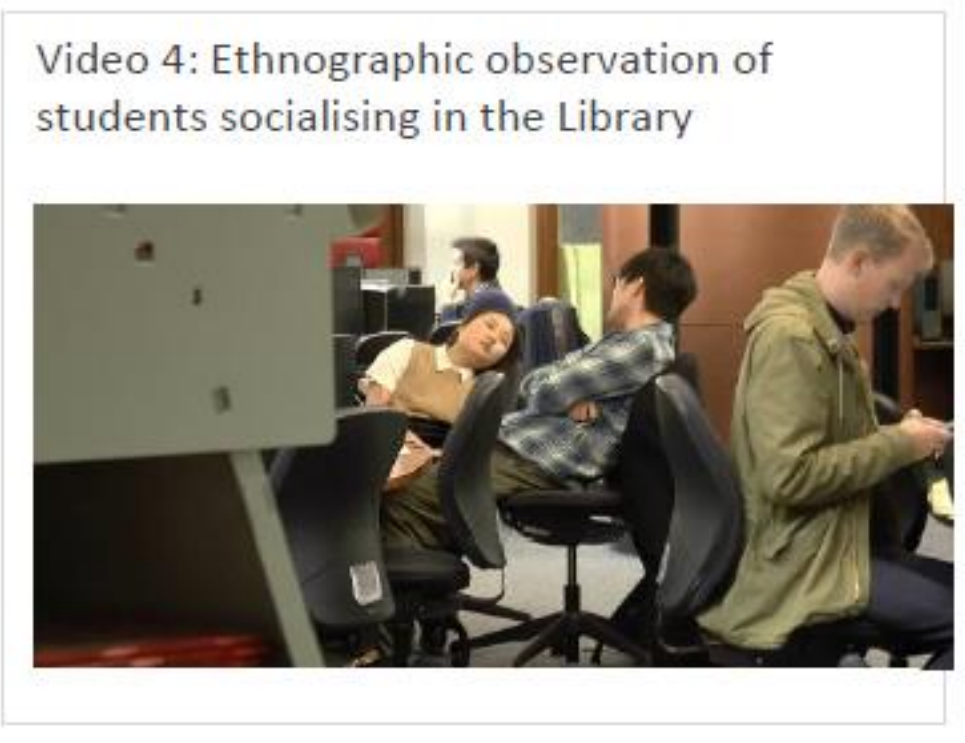

Figure 5. Photograph of Students Socialising in the Library 


\section{Using these messages to inform the redesign of spaces and services}

The results of the ethnographic work are being used to inform the redevelopment of spaces and the redesign of services. Although there is a dedicated postgraduate space in the Library clearly there is a demand for more specific space for researchers and we are considering how to provide and promote such space. Instead of desk- based enquiry and lending services, staff will be roving throughout the building, queue-busting and supporting users with self-service. Furthermore, we are evaluating our discovery services and considering taking the Library further into search engines such as Google and Google Scholar.

We also have the opportunity to explore the use of location beacons in the newly refurbished areas of the library to look at how students engage with the space. This will enables us to work in partnership with colleagues in academic departments who are interested in using the "library as a lab" for their research work in this area and to help inform wider university work on smart buildings.

\section{CONCLUSION}

It is an exciting and challenging time for UK academic libraries as they work to ensure that they can effectively support the new funder open access policies and to ensure that space and services meet the changing needs of our staff and students. The University of Glasgow Library has responded to these challenges with a strong evidence based approach which has underpinned our work in these areas and is informing our next steps. New staff roles, improved repository functionality and strong partnerships across the university will all enable us to develop and support new, necessary and valuable services for our users.

\section{References}

Ashworth, S., Mccutcheon, V., \& Roy, L. (2014). Managing open access: The first year of managing RCUK and Wellcome Trust OA funding at the University of Glasgow Library. Insights, 27(3), 282-286. doi: http://doi.org/10.1629/2048-7754.175

Association of Research Libraries. (n.d.). LibQUAL+. Retrieved from https://www.libqual.org/home

Carter, C. (2015, July 20). From a cup of coffee to a real body of feedback. Retrieved from https://www.iii.com/community/inn-side-view/cup-coffee-real-body-feedback

Finch, J. (2012). Accessibility, sustainability, excellence: How to expand access to research publications. Retrieved from http://www.researchinfonet.org/wp-content/uploads/2012/06/Finch-Group-report-FINALVERSION.pdf

Higher Education Funding Council for England. (2015). Policy for open access in the post 2014 research excellence framework: Updated July 2015. Retrieved from http://www.hefce.ac.uk/pubs/year/2014/201407/

Kiley, R., \& Marden, C. (2016, March 23). Wellcome Trust and COAF open access spend, 2014-15. [Web log post]. Retrieved from http://blog.wellcome.ac.uk/2016/03/23/wellcome-trust-and-coaf-open-access-spend-2014-15/

McCutcheon, V., \& Eadie, M. (2016). Managing open access with EPrints software: A case study. Insights, 29(1), 4552. doi: http://doi.org/10.1629/uksg.277

RCUK. (2013). RCUK policy on open access and supporting guidance. Retrieved from http://www.rcuk.ac.uk/documents/documents/rcukopenaccesspolicy-pdf/

Showers, B. (2013). The student experience and the future of libraries. Jisc Inform, 36, 10. Retrieved from https://www.jisc.ac.uk/news/the-student-experience-and-the-future-of-libraries-20-mar-2013

University of Glasgow. (n.d.). School of physics and astronomy: Professor Miles Pagett. Retrieved from http://www.gla.ac.uk/schools/physics/staff/milespadgett/ 
Wellcome. (n.d.). Charity open access fund. Retrieved from http://www.wellcome.ac.uk/About-us/Policy/Spotlightissues/Open-access/Charity-open-access-fund/

\section{About the author}

Susan Ashworth is the University Librarian at University of Glasgow Library. 